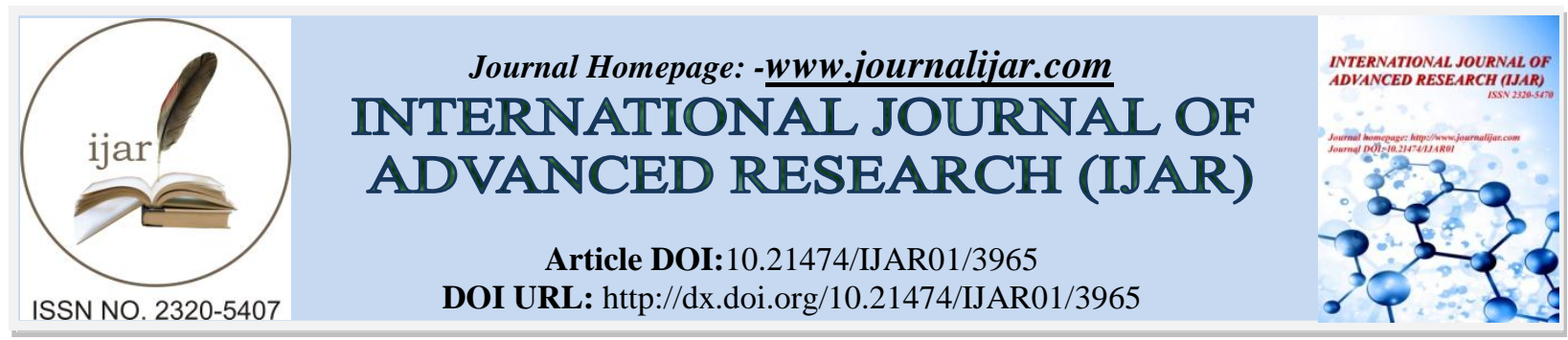

RESEARCH ARTICLE

\title{
HEALTH PROBLEMS AND BARRIERS TO ACCESS AND UTILISATION OF HEALTH CARE SERVICES AMONG STREET CHILDREN IN CAMEROON.
}

Samuel Nambile Cumber and Joyce Mahlako Tsoka-Gwegweni ${ }^{1}{ }^{*}$.

Discipline of Public Health Medicine, Department of Nursing \& Public Health, College of Health Sciences, University of Kwazulu-Natal, Durban, South Africa

\section{Manuscript Info}

Manuscript History

Received: 15 February 2017

Final Accepted: 05 March 2017

Published: April 2017

Key words:-

Street children, health problems, health care services, barriers, Cameroon

\section{Abstract}

Background: Street children in Cameroon do not form part of the national planning, resource allocation and provision of health care services because society often regards them as delinquents, a public nuisance, deviants and prospective criminals. This paper presents selfreported health conditions experienced by street children and explore the challenges they encounter when trying to seek health care in public health care facilities.

Objective: The study aimed to identify and describe health problems as well as barriers to access and utilization of health care services by street children in three cities of Cameroon.

Method: A cross-sectional study was carried out on a non-probability snowball sample of 399 street children aged 12 to 17 years. Data were collected by means of interpersonal administration of questionnaires and analyzed by uni-variate and bi-variate calculation of frequencies.

Results: Street children were highly susceptible to diverse health problems; the common ailments being malaria $(92.5 \%)$, stomach aches (90.7\%), injuries $(89.5 \%)$, skin diseases $(85.0 \%)$ and chest pain (75.9\%), and with causes involving poor health habits and risky behaviour. Self-medication was very frequent due to constraints in accessing health care services, including economic restrictions, inferior social status, long waiting times and negative attitudes of health service providers.

Conclusion: Street children are faced with numerous life-threatening and minor health problems that affect the quality of their lives. They also experience many barriers when they try to access health care services. These issues could be resolved through the development and implementation of intervention policies and integrated and accessible programmes. Since the information presented here was obtained from self-reports, which could result in under- or over-estimation of health conditions, it is recommended that further research include current measurements and tests to confirm diagnoses of the health conditions.

Copy Right, IJAR, 2017,. All rights reserved.

Corresponding Author:-Pro. Joyce Mahlako Tsoka-Gwegweni. 


\section{Introduction:-}

The number of street children continues to escalate rapidly in major cities around the world. This increase in street children population and the associated health effects are felt much more in low- and middle-income countries(1), such as Cameroon.

A literature search to obtain more information about street children in general was conducted by using databases such as Ebsco, PubMed, Scopus, AJOL, CINAHL, DIVA, ERIC and Google Scholar and choosing key words such as street children/kids/youth, health problems, health care services, barriers and Cameroon. The search for articles, journals and reports of organizations focusing on street children revealed the information presented below.

Street children are vulnerable to poor health due to their continuous exposure to harsh environments, neglect, abuse and marginalization in urban areas as well as due to their mobile and fluctuating lifestyle that greatly threatens their physical, social, mental and spiritual wellbeing(1).

Street children are more likely to experience psychological challenges, as most generally have a poor state of wellbeing, are ill and morbid. Many street children are victims of neglect, trauma and abuse and they are, therefore, susceptible to serious health challenges. Furthermore, the psychological trauma hinders adequate growth and development among this group of vulnerable and unsupervised children(2).

Street children often appear dirty, worn-out, helpless, malnourished, bitter and scared when seen in and around cities(3). Man-made circumstances have deprived them of nutrition, education, medical assistance and sanitation(3, 4). They face maltreatment on the streets, such as verbal, psychological, physical and sexual abuse, with no authority to report to(3). Hunger remains a daily challenge and some children resort to prostitution or theft to obtain food and other basic needs(3).

Lack of food exposes them to malnutrition, diseases and poor health generally, leading to stunted growth and their being underweight in some cases $(1,3)$.

Sleeping on the street is one challenge, but civic amenities, for example hygiene and sanitation facilities, are hard to afford and some children do not brush their teeth or bathe for many days or even weeks (the reason for the high prevalence of skin diseases among street children). It is also more likely that most of these children have not been vaccinated, which is coupled with poor knowledge of disease prevention $(3,5)$.

Some street children work in difficult circumstances and for long hours, putting their health at risk. Their work may include washing plates in restaurants, washing cars, guarding parked cars, assisting people to park at shopping centre's, carrying luggage, fetching water, shining shoes, selling flowers, selling sweets, working in market stalls, pick-pocketing, selling drugs, robbing stores and prostitution(4).

Continuous exposure to 'street life' may render street children vulnerable to the use of psychoactive substances(2). Abuse of any psychoactive substance (such as alcohol, tobacco, kolanut, cannabis and petrol) can be harmful to children and even deadly(2). Many African governments have done little to implement policies for preventing substance abuse, especially since these children, who are not legally of age to purchase such psychoactive substances, commonly access the substances from roadside traders, other marketing agents and peers (6).

The above-mentioned studies confirm that living on the streets makes these children habituated to drug abuse, alcoholism, smoking and chewing tobacco amongst others, leading to injuries and other illnesses that they cannot afford to treat at public hospitals due to certain barriers, such as negative attitudes from health care personnel's, high costs and long waiting times at health care centre's(7).

In order to improve the health status and wellbeing of street children, some countries like South Africa introduced intervention programmes for street children (5). In reality the plight of these children has not changed, and no such programmes currently exist in Cameroon, though in the past the Catholic Church has tried to assist these children(7). However, the lack of donor support, poor implementation of these policies and the lack of current data make it impossible for stakeholders to properly understand and address the situation $(5,8)$. 
The study aimed to identify and describe health problems as well as some barriers faced by street children to the access and utilization of health care services in three urban cities of Cameroon.

\section{Materials and Methods:-}

This study was a cross-sectional survey conducted from $1^{\text {st }}$ January to $30^{\text {th }}$ March 2015 to investigate the wellbeing and social and health status of street children in the three most densely populated cities of Cameroon. Bamenda is the most densely populated English-speaking city in the country, while Douala is the economic capital and Yaoundé the administrative capital. Both of the latter cities are predominantly French-speaking, Cameroon being a bilingual country with English and French as official languages.

A pilot study was conducted in December 2014, which was before the actual stated date of the study, using a preliminary questionnaire to identify barriers to health care services experienced by street children, the health problems they endure while living on the streets and the demographics of the study population. The questionnaire was subsequently modified by adding questions, simplifying and removing those that were too difficult for the participants to understand, considering the low literacy rate among the study population.

The selected study population was street children aged 12 to 17 years, who had spent at least one month on the streets, working or roaming around with little or no familial contact. Children living in institutions were not included for this study. Recruitment and enrolment of participant street children took place at the primary locations where street children gather, such as near train and bus stations, market and city centres and in front of film houses.

Only street children who met the study eligibility criteria of age and street residency were recruited in the study with the help of their peers and using a non-probability technique (snowball sampling method). Hence, eligible participants were asked to identify peers who met the same criteria until 405 children were recruited.

This sampling strategy was suitable because street children form a highly mobile and hard-to-reach community and due to the absence of national reports or census data on street children. Six participants were excluded due to incomplete information on the questionnaire, leaving the study with 399 participants. On the advice of an expert biostatistician from the University of Kwazulu-Natal Durban, the sample size was considered adequate to achieve the objective of the study. The children self-reported and in some cases described their conditions to the primary author and research assistants.

The Catholic Church provided private, quiet and neutral locations where the children would feel comfortable and from which the questionnaires were administered to them with the help of six trained research assistants because most of the street children could not read or write.

The study received its ethical approval from the Biomedical Research Ethics Committee, University of KwaZuluNatal, Durban, South Africa, and approval for the study was also granted by the Cameroon Bioethics Initiative(CAMBIN).

The researcher, having extensive experience working with street children and a background in social work and public health, obtained informed consent from the participants with the help of a trained and experienced clinical psychologist before each participant was allowed to participate in the study. Each participant had to understand and sign a consent form before being allowed to participate in the study.

The informed consent was obtained using the language in which the children were comfortable with (English, French or a local language). Children who were below the age of consent were not considered for the study. After the interview, refreshments were given to the participating children and other street children who happened to be around, but no monetary incentive was provided.

A structured questionnaire which was administered to the participants for collecting the data was translated into English, French and local languages; and contained questions with check boxes which took between 30 minutes to 60 minutes for each interview. The data included variables such as sex, age, religion, common infections, common non-communicable diseases, common minor ailments, risk factors for health problems, barriers to and other factors influencing access to and utilization of health care services. 
The primary outcomes of this study were the percentage of reported health problems faced by street children and the barriers they encountered in accessing health care services. The statistical analysis included uni-variate and bivariate calculations of descriptive statistics such as frequency distributions and cross tabulations used to summarize the data by implementing STATA 13.2 software. A chi-square test of association was also used to assess whether any association existed between region and other categorical variables with a $5 \%$ significance level.

\section{Results:-}

The study was conducted on 399 street children, of whom 80.2\% were male and 19.8\% female. Respondents' religious pattern showed that $82.9 \%$ were Christian, while $9.0 \%$ and $8.0 \%$ were Muslim and traditional, respectively. There were more respondents in the 15-17-year-old age group than the 12-14-year-olds (Table 1).

Table 1:- Demographic characteristics of street children in different cities in Cameroon.

\begin{tabular}{|c|c|c|c|c|c|c|c|c|}
\hline \multirow[t]{2}{*}{ Characteristics } & \multirow{2}{*}{$\begin{array}{l}\text { Total } \\
\text { No }(\%) \\
\end{array}$} & \multicolumn{2}{|c|}{ Bamenda $(n=125)$} & \multicolumn{2}{|c|}{ Douala $(n=137)$} & \multicolumn{2}{|c|}{$\begin{array}{l}\text { Yaoundé } \\
(\mathrm{n}=137)\end{array}$} & \multirow[t]{2}{*}{ p-value } \\
\hline & & No & $\%$ & No & $\%$ & $\mathrm{~N}^{\mathrm{o}}$ & $\%$ & \\
\hline \multicolumn{9}{|l|}{ Sex } \\
\hline Male & $320(80.2)$ & 108 & 86.4 & 101 & 73.7 & 111 & 81.0 & 0.035 \\
\hline Female & $79(19.8)$ & 17 & 13.6 & 36 & 26.3 & 26 & 18.9 & \\
\hline \multicolumn{9}{|l|}{ Age } \\
\hline $12-14$ & $89(22.3)$ & 29 & 23.2 & 31 & 22.6 & 29 & 21.2 & 0.919 \\
\hline $15-17$ & $310(77.7)$ & 96 & 76.8 & 106 & 77.4 & 108 & 78.8 & \\
\hline \multicolumn{9}{|l|}{ Religion } \\
\hline Christianity & $331(82.9)$ & 99 & 79.2 & 121 & 88.3 & 111 & 81.0 & 0.016 \\
\hline Islam & $36(9.0)$ & 9 & 7.2 & 13 & 9.5 & 14 & 10.2 & \\
\hline $\begin{array}{l}\text { Traditional/non- } \\
\text { religious }\end{array}$ & $32(8.0)$ & 17 & 13.6 & 3 & 2.2 & 12 & 8.8 & \\
\hline
\end{tabular}

\section{Health problems experienced by street children:-}

The results are based on self-reports which were provided by the participants. Table 2 shows that all the participants indicated that they had experienced health problems since living on the streets. For this study, an attempt was made to categorize the health problems into four major groups as experienced by participants within a month before the commencement of the study. It was noted that the total frequencies of the four categories in descending order were common or minor ailments, skin diseases, non-communicable diseases and infections.

\section{Common (minor) Ailments:-}

Common ailments included the common cold, cough, diarrhoea and various body pains. It should be noted that all of these ailments had a frequency of above $75 \%$ for the total population with the common cold and coughing being the highest, both with a frequency of $93.5 \%$. Chest pain was more prevalent in Bamenda than in Douala and Yaoundé, with the differences being statistically significant (p-value<0.001). Other common ailments with statistically significant differences between the cities included cough and headache. On the other hand, common ailments such as the common cold, back pain, stomach ache and diarrhoea were high but did not differ statistically between cities $(\mathrm{p}<0.214, \mathrm{p}<0.151, \mathrm{p}<0.488$ and $\mathrm{p}<0.331)$ respectively.

\section{Skin Diseases:-}

Among the four categories, skin diseases were reported as a common health problem in all the regions, affecting $85 \%$ of the participants. Examples of skin diseases reported in Table 2 included rashes, tinea and scabies. Similar skin diseases were reported by participants in all three cities, but with a slightly higher overall frequency in Yaoundé, although the difference was not statistically significant $(\mathrm{p}<0.252)($ Table 2$)$.

\section{Infections:-}

This category of health conditions included infections such as malaria, hair lice, sexually transmitted diseases (STDs), with the first two being the most commonly reported conditions (more than 92\% and $85 \%$ respectively). Regionally, Bamenda had a slightly lower percentage of participants reporting malaria, while Douala and Yaoundé reported equally high percentages. The p-value was 0.170 and thus no statistically significant differences were observed between the regions (Table 2). 
In contrast, slightly more children reported hair lice in Bamenda than in the other two cities and these regional differences were statistically significant $(\mathrm{p}<0.001)$. Over one third of the participants $(37.3 \%)$, reported to have suffered from STDs, with a higher number of these cases having occurred in Bamenda (Table 2).

\section{Non-communicable diseases:-}

This category included injuries, car accidents, dental, ear and eye problems, with injuries being the most common health problem reported (Table 2). Injuries (as indicated by wounds and bruises) had the highest prevalence in Yaoundé, followed by Douala and Bamenda, though the differences were not statistically significant $(\mathrm{p}<0.172)$. A slightly higher proportion of street teenagers who were involved in car/motorbike accidents were found in Bamenda. Dental problems (e.g. toothache) on the other hand differed significantly by region $(\mathrm{p}<0.05)$, being the most prevalent in Douala, followed by Yaoundé and then Bamenda (Table 2).

Table 2:- Common physical health problems experienced by street children in three Cameroonian cities.

\begin{tabular}{|l|l|l|l|l|l|}
\hline \multirow{2}{*}{ Health problem } & Total & $\begin{array}{l}\text { Bamenda } \\
(\mathrm{n}=125)\end{array}$ & $\begin{array}{l}\text { Douala } \\
(\mathrm{n}=137)\end{array}$ & $\begin{array}{l}\text { Yaoundé } \\
(\mathrm{n}=137)\end{array}$ & P-value \\
\cline { 2 - 6 } & $\mathrm{N}(\%)$ & $\mathrm{N}(\%)$ & $\mathrm{N}(\%)$ & $\mathrm{N}(\%)$ & \\
\hline 1) Skin diseases (rashes, etc. $)$ & $339(85)$ & $104(83.2)$ & $113(82.5)$ & $122(89.1)$ & 0.252 \\
\hline 2) Infections & & & & & \\
\hline Malaria & $369(92.5)$ & $111(88.8)$ & $129(94.2)$ & $129(94.2)$ & 0.170 \\
\hline Hair lice & $342(85.7)$ & $116(92.8)$ & $106(77.4)$ & $120(87.6)$ & 0.001 \\
\hline Sexually transmitted diseases & $149(37.3)$ & $95(76)$ & $23(16.8)$ & $31(22.6)$ & 0.000 \\
\hline 3) Non-communicable diseases & & & & & \\
\hline Injuries (wounds \& bruises) & $357(89.5)$ & $107(85.6)$ & $123(89.8)$ & $127(92.7)$ & 0.172 \\
\hline Car/motorbike accidents & $322(80.7)$ & $111(88.8)$ & $107(78.1)$ & $104(75.9)$ & 0.019 \\
\hline Dental problems & $353(88.5)$ & $101(80.8)$ & $128(93.4)$ & $124(90.5)$ & 0.004 \\
\hline Ear problems & $255(63.9)$ & $88(70.4)$ & $78(56.9)$ & $89(7)$ & 0.073 \\
\hline Eye disease/problems & $210(52.6)$ & $72(57.60)$ & $62(45.26)$ & $76(55.5)$ & 0.097 \\
\hline 4) Minor ailments & & & & & \\
\hline Common cold & $373(93.5)$ & $113(90.4)$ & $129(94.2)$ & $131(95.6)$ & 0.214 \\
\hline Coughing & $373(93.5)$ & $110(88)$ & $131(95.6)$ & $132(96.4)$ & 0.011 \\
\hline Chest pain & $303(75.9)$ & $110(88)$ & $99(72.3)$ & $94(68.6)$ & 0.001 \\
\hline Back pain & $327(82)$ & $109(87.2)$ & $111(81)$ & $107(78.1)$ & 0.151 \\
\hline Headache & $351(88)$ & $98(78.4)$ & $130(94.9)$ & $123(89.8)$ & 0.000 \\
\hline Stomach ache & $362(90.7)$ & $115(92)$ & $126(92)$ & $121(88.3)$ & 0.488 \\
\hline Diarrhoea & $326(81.7)$ & $98(78.4)$ & $117(85.4)$ & $111(81.0)$ & 0.331 \\
\hline
\end{tabular}

Barriers to access and utilization of health care services:-

Figure 1 shows data on the barriers to access and utilization of health care services. The availability (presence of health care facilities in the selected urban cities for the study, accessibility (easy-to-reach health care facilities in these cities), accommodation and affordability were assessed. Overall, very few participants indicated that health care facilities were available and accessible in their area of residence. Similarly, less than 5\% of participants said that health care services were affordable. Comparisons between the three cities showed that the availability, accessibility and affordability of health care services differed significantly by region. These three factors were most prevalent in Bamenda and lowest in Yaoundé (Figure 1) 
Figure 1:- Barriers to access and utilization of health care services

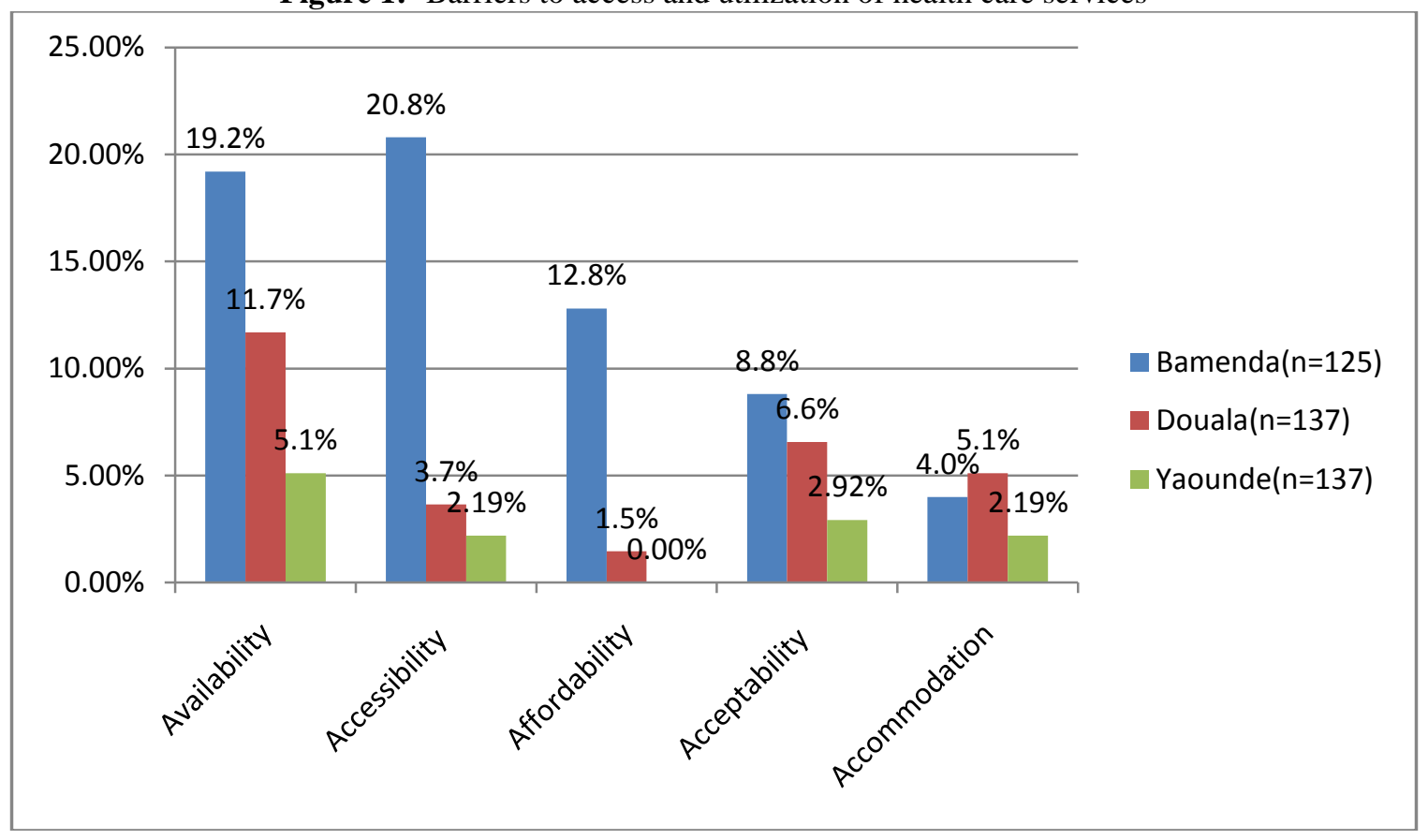

Factors identified as contributing to poor health among street children:-

The following factors were identified as contributing to poor health among street children: history of physical assault on the streets, poor sanitation, visible environmental pollution, lack of warm clothing and history of STD infection. The frequency of these factors differed significantly between the cities (Figure 2).

History of physical assault on the streets was most prevalent in Bamenda (100\%), while poor sanitation and visible environmental pollution were most common in Douala and Yaoundé. Worn-out clothing was identified as the highest contributing factor in Bamenda (75.2\%) when compared to the overall proportion of $25.5 \%$. Similarly, the history of STD infection was also most prevalent in Bamenda (44.8\%), compared to $16.0 \%$ in Douala and 19.7\% in Yaoundé. Lack of brushing teeth daily was regarded as a factor contributing the least to health problems (Figure 2). 
Figure 2:-Factors contributing to health problems among street children in three Cameroonian cities.

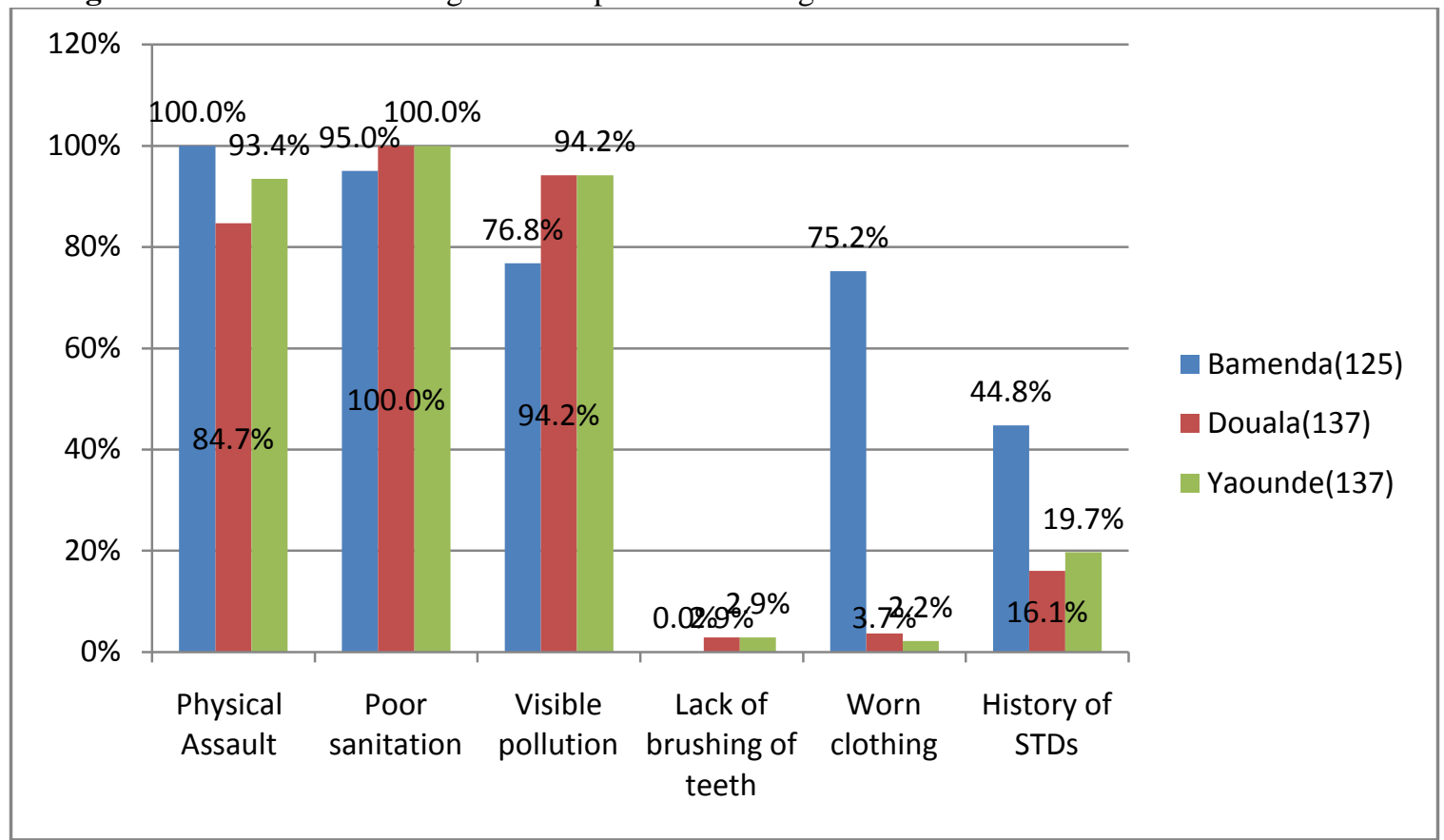

The influence of socio-cultural norms, beliefs and practices on health-seeking behaviour for treatment and prevention of health problems:-

Table 3 shows data on the influence of socio-culturalnorms, beliefs and practices on the respondents' health-seeking behaviour for the treatment and prevention of health problems. Most street children (71.7\%) said that they did not seek treatment when ill and $75.7 \%$ of the participants indicated self-treatment as a solution for illness, using easily available drugs sold on the streets without prescription, including paracetamol, ibuprofen, albendazole amongst others. These habits did not differ across the three cities, since p-values were 0.478 (for seeking no treatment) and 0.178 (for self-treatment). A very high proportion of street children (90.2\%) indicated that their peers contributed to addressing their health problems. This proportion was highest in Yaoundé (94.2\%) and Douala (91.9\%). The differences were statistically significant $(\mathrm{p}<0.015)$. There was also a sentiment that adult friends contributed to addressing health problems of street kids $(62.2 \%)$. This proportion was high in Yaoundé $(86.1 \%)$ and Douala (85.4\%), but very low in Bamenda (10.4\%). The differences among the regions were statistically significant $(\mathrm{p}<0.000)$. The majority of participants in all the cities agreed that they prayed and waited for healing from God $(85.9 \%, \mathrm{p}<0.126)$ and very few of them visited hospitals or health centres when ill $(13.3 \%, \mathrm{p}<0.770)$. The results also showed that street children visited traditional doctors/magicians when they were ill $(85.7 \%, \mathrm{p}<0.874)$. A slightly higher proportion of street children in Yaoundé (40.9\%) prayed to ancestors/dead parents for healing, compared to $35.8 \%$ in Douala and $19.2 \%$ in Bamenda. The differences among these regions were statistically significant $(\mathrm{p}<0.001)$.

Table 3:- The influence of socio-cultural norms, beliefs and practices on the health-seeking behaviour for treatment and prevention of health problems by participants

\begin{tabular}{|l|l|l|l|l|l|}
\hline \multirow{2}{*}{ Health-seeking behaviour } & Total & $\begin{array}{l}\text { Bamenda } \\
(\mathbf{n = 1 2 5})\end{array}$ & $\begin{array}{l}\text { Douala } \\
(\mathbf{n = 1 3 7})\end{array}$ & $\begin{array}{l}\text { Yaoundé } \\
(\mathbf{n = 1 3 7})\end{array}$ & P-value \\
\cline { 2 - 6 } & $\mathrm{N}^{\mathbf{o}}(\%)$ & $\mathrm{N}^{\mathbf{o}}(\%)$ & $\mathrm{N}^{\mathbf{o}}(\%)$ & $\mathrm{N}^{\mathbf{o}}(\%)$ & \\
\hline Sought treatment when ill & $113(28.3)$ & $38(30.4)$ & $37(27.0)$ & $38(27.7)$ & 0.816 \\
\hline Self-treatment when ill & $302(75.7)$ & $102(81.6)$ & $100(72.9)$ & $100(72.9)$ & 0.178 \\
\hline $\begin{array}{l}\text { Contribution of street peers in } \\
\text { addressing health problems }\end{array}$ & $360(90.2)$ & $105(84.0)$ & $126(91.9)$ & $129(94.2)$ & 0.015 \\
\hline $\begin{array}{l}\text { Contribution of adult friends in } \\
\text { addressing health problems }\end{array}$ & $248(62.2)$ & $13(10.4)$ & $117(85.4)$ & $118(86.1)$ & 0.000 \\
\hline No treatment when ill & $284(71.2)$ & $84(67.2)$ & $101(73.7)$ & $99(72.3)$ & 0.478 \\
\hline Prayers and waiting for healing & $343(85.9)$ & $101(80.8)$ & $120(87.6)$ & $122(89.1)$ & 0.126 \\
\hline
\end{tabular}




\begin{tabular}{|l|l|l|l|l|l|}
\hline from God & & & & & \\
\hline $\begin{array}{l}\text { Pray to ancestors/dead parents } \\
\text { for healing }\end{array}$ & $129(32.3)$ & $24(19.2)$ & $49(35.8)$ & $56(40.9)$ & 0.001 \\
\hline $\begin{array}{l}\text { Visit hospitals or health centres } \\
\text { when ill }\end{array}$ & $53(13.3)$ & $17(13.6)$ & $20(14.6)$ & $16(11.7)$ & 0.770 \\
\hline Visit traditional doctors when ill & $57(14.3)$ & $18(14.4)$ & $18(13.1)$ & $21(15.3)$ & 0.874 \\
\hline
\end{tabular}

\section{Discussion:-}

It is reported that the health status of street children in Cameroon was becoming a national concern as children were commonly seen all over the city centre looking very pale, ill and in a very poor hygienic state. What raised the alarm was when some of the children were found dead on the roadside $(7,8)$. This situation prompted the Cameroon government to call for urgent information on the current health problems faced by street children. The information was required in order to assist government to develop policies which could be easily implemented to improve the health of street children $(7,8,9)$.

The reason for a request for descriptive research was due to the fact that no data or any published article which had addressed the health problems of street children in Cameroon was available, thus limiting efforts to develop some interventions by stakeholders. This study was initiated as a response to the government call for current and comprehensive information on street children. Therefore, this study has described the health problems of street children and potential barriers to health care as reported by participants in the three cities of Bamenda, Douala and Yaoundé in Cameroon.

Results from the current study suggest that the health problems of street children have been neglected for some years. Though the results are limited by their descriptive nature, they are sufficient to influence policy makers to develop primary intervention for street children. This is the reason why a health promotion model has been proposed and strongly recommended to help identify determinants and factors which need intervention in order to support decision makers to address the health problems and barriers to health care services for street children in Cameroon.

Health promotion has been defined in this study as the means to empower street children to manage and make healthy lifestyle choices. For this empowerment to be accomplished, interventions strategies for street children should focus directly on their education, counseling and their type of social and economic support mechanisms. Such educational and support programmes for street children could be programmes that would improve nutrition, reduce the use of harmful psychoactive substances (tobacco, alcohol, drugs among others), as well as promote physical activities and building relationship with adults who are involved with street children like social workers, psychologists and physicians.

Some studies in South Africa and Ghana have demonstrated the use of a health promotion model by policy makers. The aim of a health promotion model is to help street children to achieve a much higher level of well-being despite the various challenges they face while on the streets, and it would encourage all stakeholders specifically health professionals to provide resources to assist street children $(8,10)$.

Results from this study show that street children suffer from numerous life-threatening and minor health problems that are more likely to affect the quality of their lives and that could lead to severe morbidity and mortality. For example, the children reported having suffered from minor ailments (75-93\%), skin diseases (85\%), noncommunicable diseases (52-89\%) and infectious diseases (24-92\%).

It is not known whether these frequencies are an under- or over-estimation of the health problems identified by the participants since these were not based on medical diagnostic tests or physical examinations. Nonetheless, these results are similar tostudies that used medical examinations of street children in Cameroon, Ghana and Sudan, which also report poor health and violation of street children's rights to health care and other basic needs, such as clean and warm clothes $(1,2,9,10,11)$. Furthermore, these other studies noted that street children lived in poor sanitary conditions, with visible pollution, including dust and smoke, especially in heavily populated industrialized cities. These conditions (lack of warm clothing, not brushing their teeth and not having a daily bath) may be the reasons for their poor general health, hygiene and oral health $(1,2,12)$. The above could also help to explain the high frequency 
of hair lice, cough and skin diseases among street children, which could be linked to unhygienic living conditions on the streets. Since street children often live in groups, it is easier to spread diseases among themselves $(4,7)$.

The results further revealed a high prevalence of malaria. Although our results are based on self-reports, Cameroon is indeed a malaria-endemic country with transmission occurring throughout the year in all areas. Malaria control initiatives in the country do not include street children, but focus on pregnant women and children living in houses with their families(12). Similarly, malaria control and elimination efforts recommended by the World Health Organization and the United Nations Children's Fund (UNICEF) do not include street children(10).

Infections such as STDs were also reported to be high in the study results. This may be partly as a result of street girls being involved in prostitution, since many regard it as a faster way to earn money for meeting their basic needs and it is also the quickest job they can find which does not require any skills or qualifications - as was also reported in a study in sub-Saharan Africa(6). Research has shown that street girls migrate to cities like Douala and Yaoundé, where there is a dense population and a demand for such work. The concern is that these girls have confirmed their engaging in unprotected sex, since clients are ready to pay more for sex without condoms and most of the street girls are not informed on the risks and consequences of having unprotected sex (15-18). It is also possible that street children may have contracted STDs through sexual assault or rape, as has been shown in other studies in India, Sudan and South Africa, and the reason could be their exposure on the streets at night(13-16).

Highest among the reported non-communicable diseases were injuries and accidents. This is not surprising as it has been shown in other studies that street children sometimes become involved in violent behaviour such as fighting and stabbing(13-16). Other reported problems, such as toothache, earache or eye problems, can be regarded as minor ailments, but were less frequently reported. Health conditions as listed under minor ailments by participants in Figure 2, were frequently reported and perhaps minor ailments were experienced due to exposure to harsh weather conditions, unclean living environments and food, air pollution and other factors which were also reported in studies conducted on street children in East Africa and Pakistan(4,7).

It is also worrying that only $20 \%$ or less of the study population said that they were able to access health care services due to several barriers, like the lack of physical accessibility to health care services; un-affordability of health care services as the cost of health care was still very expensive for street children; and the fact that the participants were neither accepted nor allowed admission (i.e. not accommodated) into health care facilities probably because of their poor dirty appearance, smell or lack of money. Similar results were also registered in other studies in East Africa and Sudan where negative attitudes towards street children were common when they went to seek health care in public health facilities, as some health care workers declined to offer medical treatment $(4,11)$.

Most of the street children practice self-treatment because of the high cost to pay for treatment in Cameroon(9). When they fall ill, they get support from their peers who assist them by getting specific herbs and grinding them with salt and water before drinking. Some street children have also resorted to traditional healers, praying to God or not seeking any treatment as shown in the results above in (Table 3).

In other countries, like the Republic of South Africa, where public health care services are free for all, the attitudes of nurses and long waiting times have been cited as barriers to health care for street children who normally earn their living from begging on the streets and doing other menial jobs(8).

As mentioned above, this study was limited by the study design that only allowed for once-off interaction with the participants without building rapport. It is possible that the participants may have given responses that under- or over-reported the results. Again, the use of questionnaires does not explore the details of some responses, which are required for further intervention, as in cases of assault, abuse or trauma.

Other studies in Africa that faced similar limitations had to first introduce the study and research team(s) to the street children by working in drop-in centres, organizing indoor and outdoor activities, as well as contacting street children in their place of gathering and providing them with food, warm clothes and other basic needs. This allowed the research assistants to build relationships with the participants before commencing data collection(13-16). However, this was not possible in the current study due to limited resources. Further research that includes qualitative methods would provide a better understanding of the comprehensive health problems faced by street children in Cameroon. 
Despite these limitations, this study provides current baseline data on street children communities in the major cities of Cameroon. These data can be used to develop strategies to prevent and treat severe diseases and eliminate mortality among street children. The results from this study can further be used to design future studies with highpowered sample sizes to fully investigate the risk factors and conduct in-depth analyses of health, social and psychological problems faced by street children, not only in Cameroon, but also in similar settings.

\section{Conclusion:-}

Living on the street under very harsh and exposed conditions, a lack of intake of correct nutrients, the abuse of substances and poor hygiene are all factors that make it very difficult for a street child to remain healthy. Although the health problems presented in this study are based on self-reports, they reflect similar problems facing street children in other parts of Africa. In addition, factors limiting access and utilization of health care services by street children included availability, accessibility, affordability, acceptability and accommodation.

The health problems faced by these children could be easily prevented if these important factors can be taken into serious consideration in designing public health policies for street children.

\section{Recommendations:-}

The recommendations made here are directed at the public sector as the main stakeholder responsible for addressing and supervising the challenges faced by street children in any country. Specifically, it is recommended that the Cameroon government works in partnership with all other stakeholders working with street children because of the complexity of their health challenges in formulating strategies on how best to address the health and social challenges faced by street children.

Providing friendly and sustainable health care services for street children and eliminating barriers to these services are critical to improve street children's quality of life in Cameroon. The government should ensure that mass awareness campaigns be launched to raise awareness in communities, including street children communities, about the detrimental effects of risky behaviour (such as involvement with drugs, alcohol abuse, gangsterism, street fighting and prostitution). We further recommend provision of user-friendly health care services and the removal of consultation fees for all vulnerable groups, especially street children. Such policies should be closely monitored and evaluated continually, ensuring that quality health care reaches street children and other vulnerable populations in Cameroon.

Because the phenomenon of street children is complex, a comprehensive intervention model should be implemented at all levels (individual, community, and national) based on multi-sectorial collaboration of all stakeholders working with street children (e.g. the government, non-governmental organizations and the community). Such a model would be suitable to address the problems of street children.

Long waiting hours in public health care facilities could be worst for marginalized populations and it also stands as a serious barrier for street children because most earn their living from begging and doing other jobs on the streets. Most of them rely on health care services offered by community-based, non-governmental and faith-based organizations like the Red Cross, Save the Children, Oxfam, Medecins Sans Frontieres and the Catholic Church(7,9).

The long waiting hours for street children could be addressed by opening a special section or prioritizing street children and other marginalized vulnerable populations as an emergency at public health care facilities in Cameroon.

However, the reports given by street children in this study need to be confirmed by further research that should include medical examinations and clinical tests focused especially on infectious diseases. It is also likely that other infectious diseases such as tuberculosis, pneumonia, HIV/AIDS, helminthiasis and schistosomiasis are highly prevalent among this group of children, which diseases the design of the present study was unable to detect. Future research supported by robust methodology and laboratory diagnoses would provide rich and important data to inform decisions regarding interventions to improve the quality of life of street children in Cameroon. 


\section{Conflict Of Interest:-}

No conflict of interest among the Authors.

No external funding

\section{References:-}

1. Matchinda B., (1999). The impact of home background on the decision of children to run away: the case of Yaounde City street children in Cameroon. Child Abuse \& Neglect Journal;23(3):245-55.

2. Tchombe TM, Nuwanyakpa M, Etmonia T., (2001). Street Children in Cameroon: Problems and Perspectives. Journal of Psychology in Africa;11(2):101-25.

3. Woods, S.B., Farineau, H.M. and McWey, L.M., (2013). Physical health, mental health, and behaviour problems among early adolescents in foster care. Child: care, health and development, 39(2), pp.220-227.

4. Seager JR, Tamasane T., (2010). Health and well-being of the homeless in South African cities and towns. Develop S Africa;27:63-83.

5. Nsagha, D. S., \& Thompson, R. B., (2011). Integrated care of orphans and vulnerable children in Ekondo Titi and Isangele Health Areas of Cameroon. Journal of HIV/AIDS \& Social Services; 10(2), 161-173.

6. Woolf-King SE, Maisto SA., (2011).Alcohol use and high-risk sexual behavior in Sub-Saharan Africa: a narrative review. Archives of sexual behavior;40(1):17-42.

7. Strehl, Talinay., (2010). "Street-Working and Street-Living Children in Peru: Conditions and Current Interventions." IREWOC Research Project on Street Children in Peru.

8. Cluver, L. D., Orkin, M., Gardner, F., \& Boyes, M. E., (2012). Persisting mental health problems among AIDS-orphaned children in South Africa. Journal of Child Psychology and Psychiatry; 53(4), 363-370.

9. Maslow, G. R., \& Hill, S. N., (2016). Systematic review of character development and childhood chronic illness. World Journal of Clinical Pediatrics, 5(2), 206-211. http://doi.org/10.5409/wjcp.v5.i2.206.

10. Oppong Asante, K., Meyer-Weitz, A., \& Petersen, I., (2014). Substance use and risky sexual behaviours among street connected children and youth in Accra, Ghana. Substance Abuse Treatment, Prevention, and Policy, 9 , http://doi.org/10.1186/1747-597X-9-45.

11. Plummer ML, Kudrati M, Dafalla El Hag Yousif N., (2007).Beginning street life: Factors contributing to children working and living on the streets of Khartoum, Sudan. Children and Youth Services Review;29(12):1520-36.

12. Nsamenang AB., (2000). Fathers, Families, \& Child Well-Being in Cameroon: A Review of the Literature.

13. Mathur M, Rathore P, Mathur M., (2009). Incidence, type and intensity of abuse in street children in India. Child Abuse \& Neglect; 33(12):907-13.

14. Kudrati M, Plummer ML, Yousif Ndeh., (2008).Children of the sug: A study of the daily lives of street children in Khartoum, Sudan, with intervention recommendations. Child Abuse \& Neglect Journal;32(4):439-48.

15. Chireshe, Regis; Jadezweni, Jay M. M.; Cekiso, Mzwamadoda; Maphosa, Cosmas., (2010). Poverty: Narratives and Experiences of Street Children in Mthatha, Eastern Cape, South Africa. Journal of Psychology in Africa; Vol.20(2), p.199-202.

16. Owoaje E, Uchendu O., (2009). Sexual risk behaviour of street youths in southwest Nigeria. East Afr J Public Health;6:274.

17. Habtamu, D., \& Adamu, A., (2013). Assessment of Sexual and Reproductive Health Status of Street Children in Addis Ababa. Journal of Sexually Transmitted Diseases, 2013, 524076. http://doi.org/10.1155/2013/524076.18.Mandalazi P, Banda C, Umar E., (2013).Street children's vulnerability to HIV and sexually transmitted infections in Malawian cities. Malawi medical Journal. DOI: http://dx.doi.org/10.4314\%2Fmmj.v25i1. Volume 25(1): pp1- 4

18. Gupta and Anjali., (2012). Social Determinants of Health - Street Children at Crossroad: Health (1949 - 4998); volume 4, Issue 9, Pages 634-643. 